\title{
AUTOMATIC GENERATION CONTROL OF A MULTI-AREA POWER SYSTEM BASED ON GREY WOLF OPTIMIZATION ALGORITHM
}

${ }^{*}$ Hussein H. Jaber ${ }^{1}$

1)

Electrical Engineering Department, College of Engineering, Mustansiriyah University, Baghdad, Iraq

\begin{abstract}
This paper presents an automatic generation control algorithm applicable for a multi-area power system. A more practical models is used to represent the main components of the power system. The frequency bias factor (B) is set optimally by using an artificial intelligence technique. The generation rate constraints (GRC) are taken into consideration with dead band characteristics of the governor. For the first time, a sequential optimization of the fractional order (PID) control parameters, the governor speed regulation $(R)$ and the frequency bias factor (B) is proposed. The objective function to be minimized is the updated integral time absolute error (UITAE). The tuning of the control parameters is dependent on minimizing the objective function by using the Grey wolf optimization (GWO) algorithm. The proposed algorithm is tested on an interconnected three power pools different system (Reheat, Gas and Hydro) with varying degrees of load step change. The simulation results of the presented process are compared to those achieved by using the particle swarm optimization method. The results obtained reveal the robustness of the proposed algorithm in terms of settling time and peak overshoot.
\end{abstract}

Keywords: frequency bias factor, automatic generation control, fractional order, multi-area, gray wolf

\section{Introduction}

Automatic generation control (AGC) or load frequency control is vital in power system operation. The aim of AGC is to keep the frequency and the power exchange lines between them at their nominal values, regardless of small load variations. There are two signals of concern for each area, the frequency variance and the deviation of the power exchange of the tielines coming from the area. Their measured combination is a single control power signal called Area Control Error (ACE). Frequency bias factor (B) applies to the weight of the frequency deviation. To avoid any mismatch between total active power production and total active power demand with losses, an active AGC system should chase load variability and follow generation units. There has been a lot of researchers [1-16] in the area of AGC in the past. The problem was addressed by applying the principles of centralized and decentralized controllers. The AGC method has been studied from the perspective of efficient linear regulator architecture by a number of researchers [1-10]. In [11-12], an algorithm for developing a sliding mode controller (SMC) for an AGC system was suggested. Adaptive load frequency controllers were proposed to account for parametric instability, it focused on various publications [13-17]. Ref [20] was highlighted a literature review on different control methods used in AGC of power systems. The strategies used in AGC were the subject of reference [21].

*Corresponding Author: husseinmosawy.1987@gmail.com 
It also emphasized the usage of energy storage systems in AGC. Alovic'et.al [22] established a tool to fix systemic errors in load frequency controllers induced by tie line losses. Other researchers [23-31] used a conventional PID controller to solve the AGC problem. Bacterial foraging [23,25], Firefly Algorithm [24], Genetic Algorithm [25], Artificial Bee Colony algorithm [27], Evolutionary computation [28], Gases Brownian Motion Optimization (GBMO) [29], quasi-oppositional harmony quest algorithm [30], imperialist competitiveness algorithm [31] were some of the swarm's artificial intelligence used to tune the control parameters. Several smart control strategies have been suggested to elimination the drawback conventional LF controllers. Any of them were developed using the two-degree-of-freedom controller and fractional order PID controller [ 32]. Other techniques included using an alternative derivative filter [35-36] or cascading traditional controllers [33-34]. Kothari et al. [37] analyzed the effect of GR controller and sampling time on the efficiency of automatic generation control. an investigation of the proper selection of the speed control (R) of a thermal system showed by [38]. In [39-43] was introduced for the application of fuzzy logic theory in LF controller. ANN-based load frequency controllers were suggested by some researchers [44]. It was discovered that utilizing a two-level organized control approach based on the several Agent System (SAS) methods by [45] would handle the conflicts between frequency control and ACE control of the autonomous controller. Recently, a sequential optimization of the major load frequency regulation with the parameters of the PID controllers has interested many researchers [ 4647]. It was discovered that setting the droop regulation optimally by sequential tuning of the controller parameters and the speed regulation improved in the AGC dynamic efficiency. the bias frequency factor(B) hasn't widely studied. It has been said that the frequency bias factor (B) has a noticeable effect on the system's dynamic control. as well as, in [50] it was proposed that half of the frequency response properties $\beta$ is to be set at the best value for the frequency bias component. The goal of this study is to optimize the frequency bias factor(B). This is achieved through a FOPID controller with AGC system. Sequential tuning of frequency droop and frequency bias factor for the controller parameters must be carried out by minimizing grey wolf optimization (GWO) algorithm [18] based on the output index. A composite three-area power pools (Thermal, Gas and Reheat) whose data is given in [48] is used for the application of the proposed technique. A practical model of the load frequency control system elements includes dynamics of boiler, a non-linear dead band governor, and generation rate constraints are used. The article is arranged accordingly; The mathematical model of the load frequency control system elements is presented in Section 2. In Section 3 includes the structure of the PID fractional order controller. In Section 4 provides a study of the Grey wolf optimization (GWO) algorithm. The simulation of the test system is defined in Section 5. This part also provides a discussion of the findings collected. Conclusion is outlined in Section 6.

\section{Mathematical Modeling for the Investigated Power System}

Three different power pools exist in this paper (Reheat, Gas and Hydro). The three power pools have a total of $8000 \mathrm{MW}, 4000 \mathrm{MW}$, and 2000 MW, sequentially. The Reheat, Gas and Hydro models' turbines are used in these power fields. An effective transfer function is used to model the elements in each power area as seen in Figure.1. The mathematical model of AGC takes the following physical nonlinear constraints [53-54]. 


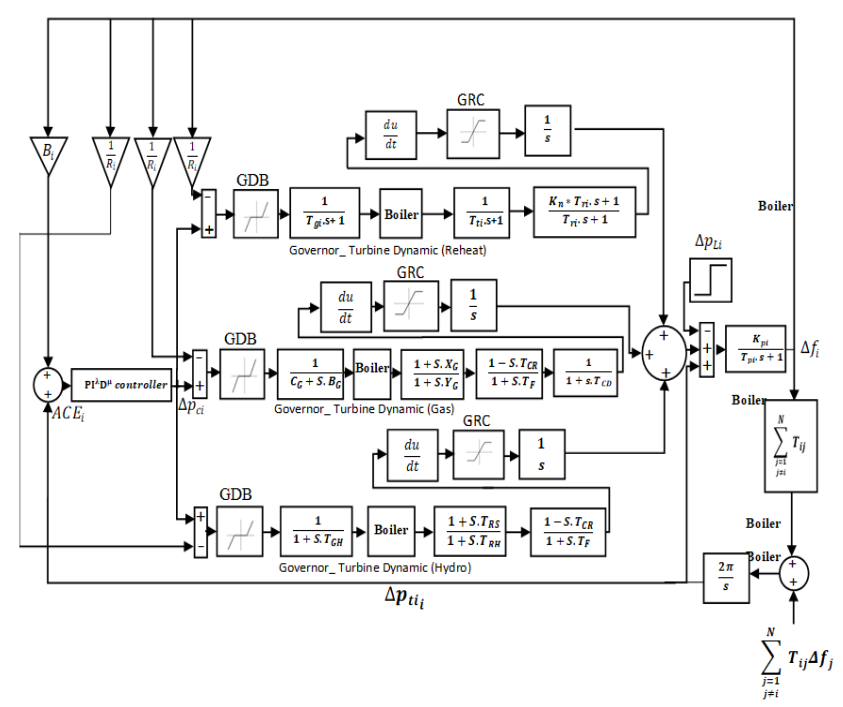

Figure 1. Transfer function of three power pool-hybrid with nonlinearities.

\subsection{The Boiler's Nonlinear Dynamics}

A boiler is a steam generator that produces pressurized steam. The thermal turbine units in this paper are presumed to have a recirculation boiler, whose transfer function is provided in Appendix. A gas or oil-fired boiler is being used to achieve load demand requirements for a faster response than other systems. A drum-type boiler is considered in this study. Pressure is used in the long-term dynamics of fuel and steam movement on the boiler tank. Figure.2 [50] shows a model of a recirculation boiler. They are the major components of Figure 1 power structure.

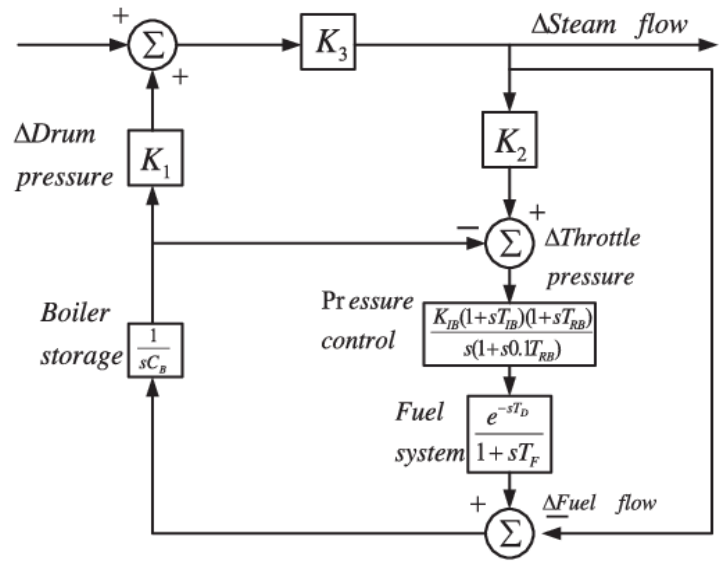

Figure 2. Dynamic boiler diagram.

\subsection{The Generation Rate Constraint (GRC)}

In a steam plant, the rate of change of the power is limited. If this rate is not taken into consideration, the LFC may happen disturbances major transient fluctuations. The literature shows that the generation rate restriction has a major effect on the AGC's dynamic efficiency. A dynamic response of GRC characteristics which have a longer settling period and a greater peak overshoot. A GRC of 0.1 p.u. per minute is used and modelled in this work, as seen in Figure 3.

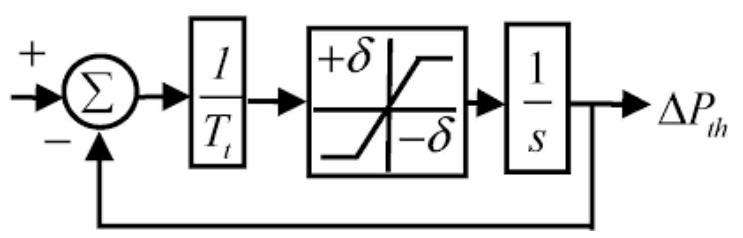

Figure 3. Turbine model with GRC.

\subsection{The Governor Dead Band (GDB)}

The dead band (backlash) can be known is the range which the load frequency controller may allow the frequency to deviate without taking any control action and as shown in Figure 4.

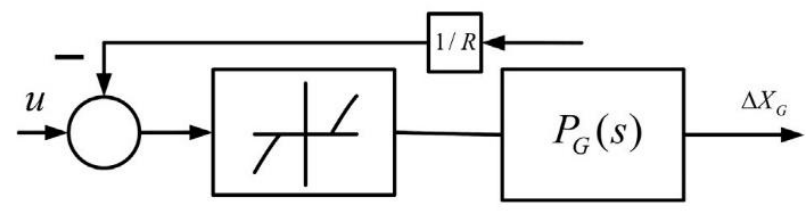

Figure 4. Dead-band in governor control loop.

\section{The Fractional Order PID Controller}

Fractional order PID controller $\left(P I^{\lambda} D^{\mu}\right)$ may be showed by equation (1) [50]:

$u(t)=e(t)\left\{K_{p}+K_{i} D_{t}^{-\lambda}+K_{d} D_{t}^{\mu}\right\}$

Where $\mathrm{u}(\mathrm{t})$ is the regulation signal and $\mathrm{e}(\mathrm{t})$ are the error signal. The error signal $\mathrm{e}(\mathrm{t})$ in this study is the Area Control Error (ACE). Transform eq (1) to Laplace domain equations and given the original zero. The transfer function T.F requirements can be defined by eq. (2) as follow: 


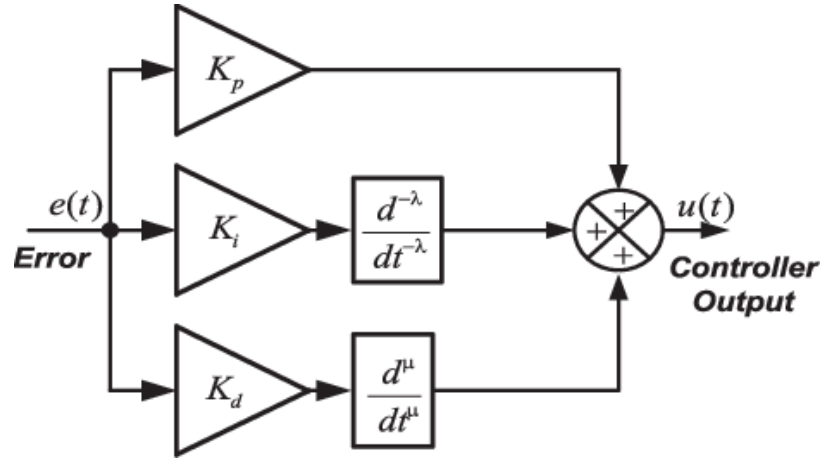

Figure 5. Controller Scheme Investigated

$g_{c}(s)=K_{p}+K_{i} s^{-\lambda}++K_{d} s^{\mu}$

To reduce calculation time, noise effects, and the System Influence of different nonlinearities. The action is set to the derivative fractional a simple filtered derivative process $(\mu=1)$. The transition function TF of the studied controller is published in the following way:

$g_{c}(s)=\frac{u(s)}{e(s)}=K_{p}+K_{i} s^{-\lambda}+K_{d} \frac{S N}{S+N}$

where $\boldsymbol{g}_{\boldsymbol{c}}(\mathrm{s})$ is the controller output, $\mathrm{u}(\mathrm{s})$ is the control signal, e(s) is the error signal, $K_{p}$ is the proportional control error constant gain, $K_{i}$ is the integrated constant gain, $K_{d}$ is the derivative constant gain, $(\lambda)$ is the order of integration and $(\mu)$ is the order of differential. The conversion role of the analysed controller and of the investigated controller Plane representation of various integer and fractional forms. Figures 5 represent the controller scheme of FOPID.

\section{Objective Function}

The main purpose objective of the automatic generation control system is to adjust the parameters of the controllers to maintain the frequency and the interchange power in the scheduled values. For this study, so as to meet the desired requirements such as lower overshoot, fast settling time and lower error, it is very important to define an objective function. In many previous studies, the integral time multiplied absolute error (ITAE) is generally used as an objective function and is given by:
$\boldsymbol{I T A E}=\int_{0}^{t s}\left\{\left|t\left(\Delta f_{1}\right)\right|+\left|t\left(\Delta f_{2}\right)\right|+\left|t\left(\Delta f_{3}\right)\right|\right\} d t$

The ITAE objective function will minimize the settling time, but it can't reduce the overshoot properly. To do this, this paper proposes an updated UITAE objective function that includes an overshoot minimizing of the system and the faster settling time and as shown in eq.5.

$$
\begin{aligned}
& \boldsymbol{U I T A E}=\int_{0}^{t s} t\left\{\sum _ { i = 1 } ^ { 3 } \left\{\left|\Delta f_{\mathrm{i}}\right|+\left|\Delta P_{\text {tie-i }}\right|+\right.\right. \\
& \left.\operatorname{Max}\left|\Delta f_{\mathrm{i}}\right|+\operatorname{Max}\left|\Delta P_{\text {tie-i }}\right|\right\} d t
\end{aligned}
$$

The optimization problem can be expressed in the model:

\section{$\operatorname{Minimize}\left(K_{p}, K_{d}, K_{i}, \lambda, \mu, N, \beta\right.$ and $\left.b\right)$}

\section{Subject to:}

$$
\begin{aligned}
& K_{p}^{\text {min }} \leq K_{p} \leq K_{p}^{\text {max }} \\
& K_{i}^{\text {min }} \leq K_{i} \leq K_{i}^{\text {max }} \\
& K_{d}^{\text {min }} \leq K_{d} \leq K_{d}^{\text {max }} \\
& \lambda^{\text {min }} \leq \lambda \leq \lambda^{\text {max }} \\
& \mu^{\text {min }} \leq \mu \leq \mu^{\text {max }} \\
& R^{\text {min }} \leq R \leq R^{\text {max }} \\
& Y^{\text {min }} \leq \mathrm{B} \leq \Upsilon^{\text {max }}
\end{aligned}
$$

Where $\boldsymbol{K}_{\boldsymbol{p}}, \boldsymbol{K}_{\boldsymbol{i}}, \boldsymbol{K}_{\boldsymbol{d}}$ are the controller parameters, the integral fraction $(\lambda)$ is a factor, $\boldsymbol{\beta}$ is an area frequency response and equal to $(D+1 / R)$, D: sensitivity system, $\left.\quad\left(=\Delta \boldsymbol{P}_{\boldsymbol{D} \boldsymbol{i}} / \Delta \boldsymbol{f}_{\boldsymbol{i}}\right)\right], \mathbf{B}$ is a frequency bias constant of area and it limits are between $\left(\mathbf{\Upsilon}^{\min }=0.1 \beta^{\min }, \mathbf{\Upsilon}^{\max }=1.5 \beta^{\max }\right)$, [24-53], we could calculate the optimal value in each area, $(\mu)$ is the order of differential, it is presumed to be equivalent to 1 .

\section{Gray Wolf Optimization}

Grey wolf optimization is attempted for LFC in this paper. This algorithm was submitted to the behaviour of Grey Wolves.[19]. Grey wolves are known to be strongest of all and find what we need. Figure 9.

Alpha is the powerful and strongest member of the pack and it may be a male or a female. Decisions about migration, choosing home, hunting made by the alpha wolf. The Alpha 
wolf who is best in controlling the pack but not essentially it can be strongest member of the pack, which means that organization is better than strength. Beta wolf is the second level in the hierarchy. When wolf makes choices, the function of beta wolf is to assist lpha. When the alpha wolf is sick or died, beta Wolf will lead the pack in addition to being an advisor to alpha Wolf. Delta wolves are in the third level in the hierarchy. the duties of delta are making report to alpha and beta wolves. hunters and caretakers belong to delta third. Omega is the lowest ranked in the hierarchy. The importance of these wolves is that due to keep out problems and fighting in the pack.

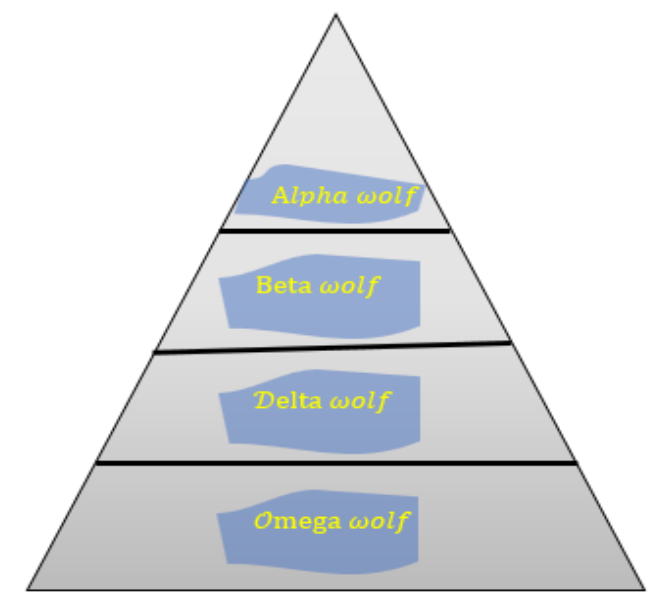

Figure 6. Grey wolves' hierarchy.

\subsection{Mathematical Model of GWO}

In this part, the social order of wolves, chasing, circling and attaching a victim are mathematically modelled, [19].

\subsubsection{Social Hierarchy}

The first optimal is called alpha, the second best is beta, the third best is delta wolves, while the rest of the pack's solutions are called Omega wolves throughout this optimization technique.

\subsubsection{Encircling}

During circle the victim by the Gray wolves is considered mathematical model.

$\bar{R}=\left|\bar{L} \cdot \bar{Y}_{P}(t)-\bar{Y}(t)\right|$
$\bar{Y}(t+1)=\bar{Y}_{P}(t)-\bar{M} \cdot \bar{R}$

Where $\bar{Y}_{P}(t)$ remark to current location of prey and $\mathrm{t}$ remark current iteration. The following equations used to calculate the values of $M$ and L.

$\bar{M}=2 \bar{q} \cdot \bar{f}_{1}-\bar{q}$

$\bar{L}=2 \cdot \bar{f}_{2}$

the random vectors are $\mathrm{f} 1, \mathrm{f} 2$ in $[0,1]$. As number of iterations progresses, the value of $(q)$ decreases linearly from 2 to 0 and is defined as:

$\bar{q}=2-2\left(\frac{\text { iteration }_{\text {iteration }^{\max }}}{\text { te }^{2}}\right)$

Where iteration and iteration maximum represent current iteration and maximum number of iterations, sequentially. The limited of $\bar{M}$ is $[-2 \bar{q},+2 \bar{q}]$

\subsubsection{Hunting}

The capacity of the Grey wolves is to recognize the prey position and encircle the prey. With the given equation in the Encircling phase, the grey wolves relocate their location to anywhere in the work space. As mentioned above, for remain of the pack and for hunting procedures, social hierarchy consider a key role. The mathematical model of hunting procedures of the $\mathrm{GW}$ has been shown in $[19,26]$. The formulas for new the location are as follows.

$\bar{Y}(t+1)=\frac{\bar{Y}_{1}+\bar{Y}_{2}+\bar{Y}_{3}}{3}$

The values of $\bar{Y}_{1}, \bar{Y}_{2}$ and $\bar{Y}_{3}$ are calculated as

$\bar{Y}_{1}=\bar{Y}_{\alpha}-\bar{M}_{1} \cdot \bar{R}_{\alpha}$

where $\bar{R}_{\alpha}=\left|\bar{L}_{1} \cdot \bar{Y}_{\alpha}-\bar{Y}\right|$

$\bar{Y}_{2}=\bar{Y}_{\beta}-\bar{M}_{2} \cdot \bar{R}_{\beta}$

where $\bar{R}_{\beta}=\left|\bar{L}_{2} \cdot \bar{Y}_{\beta}-\bar{Y}\right|$

$Y_{3}=Y_{\delta}-M_{3} \cdot R_{\delta}$

where $\bar{R}_{\delta}=\left|\bar{L}_{3} \cdot \bar{Y}_{\delta}-\bar{Y}\right|$

5.1.4 Attacking Prey (exploitation) 
As shown above, one time the prey stops moving, the GW hunt and encircle the prey. The hunting operation gets ended by attacking the prey. The mathematical model of approximation the prey is modeled by decreasing the value of $\bar{q}$, that in turn decrease the fluctuation range of $\bar{M}$ in the arbitrary value interval of [ -22$]$. The discovery of prey is ensuring when the value of $M$ greater than one or M less than minus one and using it and ensure when $-1<\mathrm{M}<1$. The algorithms finding out and using behavior submit on the value of $M$ has been submitted by running the program 5 times in the reference [26]. Although the agents update their location for attacking the prey, submit on the position of alpha, best and beta wolves and the values of parameters $\bar{M}, \bar{R}$ and $\bar{q}$, the algorithm exposed to slump at local optimal. Thus, there is a need for more parameters for discovery.

\subsubsection{Search for Prey (Exploration)}

As well as to the parameters defining above, there is another parameter valid discovery of the algorithm is $\bar{L}$. The values of $\bar{L}$ different randomly in [0 2] in differing with $\bar{q}$, which decreases linearly from 2 to 0 . The contribution of prey in limiting the next location of wolves is decided by the value of $\bar{L}$. When the value of parameter $\bar{L}>1$, the wolves were attracted more towards the prey. The value of $\bar{L}$ is randomly created through the algorithm, the emphasis is more towards discovery from beginning to final iteration to avoid local optimal.

\subsection{Grey Wolf Optimization Controller Algorithm for AGC Problem}

As mentioned above, in this study Gray Wolf Optimization controller has been implemented for optimum tuning of fractional PID controller $\left(\mathrm{PI}^{\lambda} \mathrm{D}^{\mu}\right)$ gains for AGC of stand-alone microgrid and multi-microgrid systems. The algorithm carries out steps are enumerated as following:

1. Population size $\left(p^{\text {size }}\right)$, iteration ${ }^{\max }$, number of controls variable(n), (i.e.; $k_{p}, k_{d}$, $k_{i}, \lambda$ and $\mu$ for each controller), boundaries of fractional PID controller $\left(\mathrm{PI}^{\lambda} \mathrm{D}^{\mu}\right)$ gains $\left(K_{p}^{\min , \max }, K_{I}^{\min , \max }, K_{D}^{\min , \max }\right.$

$\lambda^{\text {min,max}}$ and $\mu^{\text {min,max }}$ )

2. Create the population (Pop) randomly inside their boundaries.

3. Play the Simulink program and assess the fitness (UITAE) values for all the populations by the Equation 5 .

4. Sorting the population depending to fitness. Assign alpha, beta, delta \& Omega wolves based on fitness values.

5. Refresh the location of alpha, beta, delta grey wolves based on fitness value as following:

For $i=1$ to $p^{\text {size }}$

if ( fitness ( pop $(i))<$ fitness (alpha)

alpha $=\operatorname{pop}(i)$

End

if ( fitness $(\operatorname{pop}(i))$

$>$ fitness (alpha) and fitness $(\operatorname{pop}(i))$

$<$ fitness (beta)

beta $=\operatorname{pop}(i)$

End

if (fitness ( pop $(i))>$ fitness (alpha) and

fitness $(\operatorname{pop}(i))>$ fitness (beta) and

fitness $(\operatorname{pop}(i))<$ fitness $($ delta $)$

delta $=\operatorname{pop}(i)$

End

End

6. Refresh the position of Omega grey wolves by use the Equations (13-15).

7. Refresh the control variables using Equation 13 and verify whether they are violating their boundaries. If violated, keep within their boundaries.

8. Move to step (3) and returns the above steps until convergence criteria are complacent.

Table 1. Parameters of GWO

\begin{tabular}{ll}
\hline Parameters & Value \\
\hline Number of generations & 400 \\
Population sizes & 40 \\
Crossover probability & 0.85 \\
Mutation probability & 0.65 \\
\hline
\end{tabular}




\section{Result and Discussion}

Using the MATLAB/SIMULINK toolbox, extensive simulation is carried out to apply the presented algorithm on a three-power pool for (Reheat, Gas and Hydro) systems shown in Figure.1. The dynamic performance obtained by using a fractional PID controller are obtained by using a traditional PID controller so as to test the robustness of the fractional PID controller. The efficiency of the Grey wolf optimization (GWO) mechanism is determined by comparing the results to those obtained using the PSO algorithm as an optimization method. The disturbance in the active power demand is simulated by a step change of $1 \%$ in the load demand. There are a many different operational scenarios which are investigated. The controller's benefits, droop regulation $\mathrm{R}$, and frequency bias factor $\mathrm{B}$ are all optimally obtained in each scenario. The minimized performance to be in the presented algorithm is the updated integral time absolute errors (UITAE), that are given as follow:

$\boldsymbol{U I T} \boldsymbol{A} \boldsymbol{E}=\int_{0}^{t s} t\left\{\sum_{i=1}^{3}\left\{\left|\Delta f_{\mathrm{i}}\right|+\left|\Delta P_{\text {tie-i }}\right|+\right.\right.$ $\left.\operatorname{Max}\left|\Delta f_{\mathrm{i}}\right|+\operatorname{Max}\left|\Delta P_{\text {tie-i }}\right|\right\} d t$

Table 2. Optimal controller settings determined by the GWO.

\begin{tabular}{ccccc}
\hline $\begin{array}{c}\text { Controller } \\
\text { parameter }\end{array}$ & $\begin{array}{c}\text { Controller } \\
\text { types }\end{array}$ & Area-1 & Area-2 & Area-3 \\
\hline$k_{p}$ & $P I D$ & 6.2568 & 5.2654 & 1.1586 \\
& $P I^{\lambda} D^{\mu}$ & 3.2687 & 0.2002 & 11.257 \\
$k_{i}$ & $P I D$ & 12.244 & 4.1245 & 0.1202 \\
& $P I^{\lambda} D^{\mu}$ & 15.262 & 11.786 & 14.101 \\
$k_{d}$ & $P I D$ & 3.4577 & 7.1254 & 1.0012 \\
& $P I^{\lambda} D^{\mu}$ & 4.4511 & 7.1452 & 6.2575 \\
$\lambda$ & $P I D$ & 0.8020 & 0.6524 & 0.6235 \\
& $P I^{\lambda} D^{\mu}$ & 0.7525 & 0.2575 & 0.9444 \\
$\mu$ & $P I D$ & 0.4215 & 0.8000 & 0.7250 \\
& $P I^{\lambda} D^{\mu}$ & 0.9945 & 0.6250 & 0.7582 \\
$R$ & $P I D$ & 2.1450 & 2.0235 & 8.009 \\
& $P I^{\lambda} D^{\mu}$ & 2.0121 & 2.0500 & 3.0521 \\
$\beta$ & $P I D$ & 0.8565 & 1.2500 & 1.9850 \\
& $P I^{\lambda} D^{\mu}$ & 0.8547 & 1.4258 & 1.4512 \\
\hline
\end{tabular}

Table 3. Optimal controller settings determined by the PSO.

\begin{tabular}{ccrcc}
\hline $\begin{array}{c}\text { Controller } \\
\text { parameter }\end{array}$ & $\begin{array}{c}\text { Controller } \\
\text { types }\end{array}$ & Area-1 & Area-2 & Area-3 \\
\hline$k_{p}$ & $P I D$ & 5.5251 & 7.2541 & 2.2542 \\
& $P I^{\lambda} D^{\mu}$ & 5.7750 & 2.0001 & 15.001 \\
$k_{i}$ & $P I D$ & 18.001 & 5.2548 & 1.2100 \\
& $P I^{\lambda} D^{\mu}$ & 16.562 & 10.254 & 13.001 \\
$k_{d}$ & $P I D$ & 3.7861 & 5.2565 & 0.0001 \\
& $P I^{\lambda} D^{\mu}$ & 3.1323 & 5.5685 & 6.7621 \\
$\lambda$ & $P I D$ & 0.7411 & 0.5477 & 0.7106 \\
& $P I^{\lambda} D^{\mu}$ & 0.5852 & 0.5256 & 0.9666 \\
$\mu$ & $P I D$ & 0.9879 & 0.7809 & 0.7855 \\
& $P I^{\lambda} D^{\mu}$ & 0.9945 & 0.7756 & 0.8511 \\
$R$ & $P I D$ & 2.0012 & 2.2501 & 8.8526 \\
& $P I^{\lambda} D^{\mu}$ & 5.2586 & 2.5200 & 3.2500 \\
$\beta$ & $P I D$ & 0.77195 & 1.5004 & 1.0250 \\
& $P I^{\lambda} D^{\mu}$ & 0.65018 & 1.4782 & 1.2583 \\
\hline
\end{tabular}

\subsection{The First Scenario}

In this scenario, a few step load increases of $1 \%$ $\Delta P_{D 1}$ is happened in power pool 1 (Reheat, Gas and Hydro). The frequency deviation for dynamic response and exchange in the tie-lines power are shown in figures 7-12. The frequency bias factor (B) along with the droop regulation factor (R) are optimal synchronously with the controller parameters as in the table-2. The optimal result of the frequency bias factors for the scenario are found to be $\mathrm{B}_{1}{ }^{*}=0.40248 \mathrm{p} . \mathrm{u}$ $\mathrm{MW} / \mathrm{Hz} \quad, \mathrm{B}_{2}{ }^{*}=0.65841$ p.u $\mathrm{MW} / \mathrm{Hz}$, and $\mathrm{B}_{3}{ }^{*}=0.71611$ p.u $\mathrm{MW} / \mathrm{Hz}$.It is obvious from these figures that the suggested $P I^{\lambda} D^{\mu}$ controller using GWO provides best dynamic characteristics in terms of damping all oscillations, minimizing decreasing overshoot and settling time. 
Table 4. Fitness value

\begin{tabular}{llllll}
\hline & $\begin{array}{l}\text { Controller } \\
\text { parameter }\end{array}$ & UITAE & S.T(s) & $\begin{array}{l}\text { Oversh } \\
\text { oot }\end{array}$ & $\begin{array}{l}\text { Undersho } \\
\text { ot }\end{array}$ \\
\cline { 2 - 6 } Area-1 & FOPID- & 0.7652 & 6.254 & 0 & 9.786 \\
& FOPID-PSO & 0.9002 & 11.58 & 6.256 & 13.130 \\
& PID-GWO & 2.3899 & 10.06 & 4.758 & 13.300 \\
& PID-PSO & 3.7014 & 11.55 & 5.854 & 13.845 \\
Area-2 & FOPID- & - & 8.950 & 0 & 0.00194 \\
& FOPID-PSO & - & 13.12 & 0.0006 & 0.00524 \\
& PID-GWO & - & 15.15 & 0.0014 & 0.00282 \\
& PID-PSO & - & 13.11 & 0.0016 & 0.00400 \\
Area-3 & FOPID- & - & 8.852 & 0 & 0.00221 \\
& FOPID-PSO & - & 12.45 & 0.0011 & 0.00440 \\
& PID-GWO & - & 14.35 & 0.0003 & 0.00385 \\
& PID-PSO & - & 18.86 & 0.0014 & 0.00174 \\
\hline
\end{tabular}

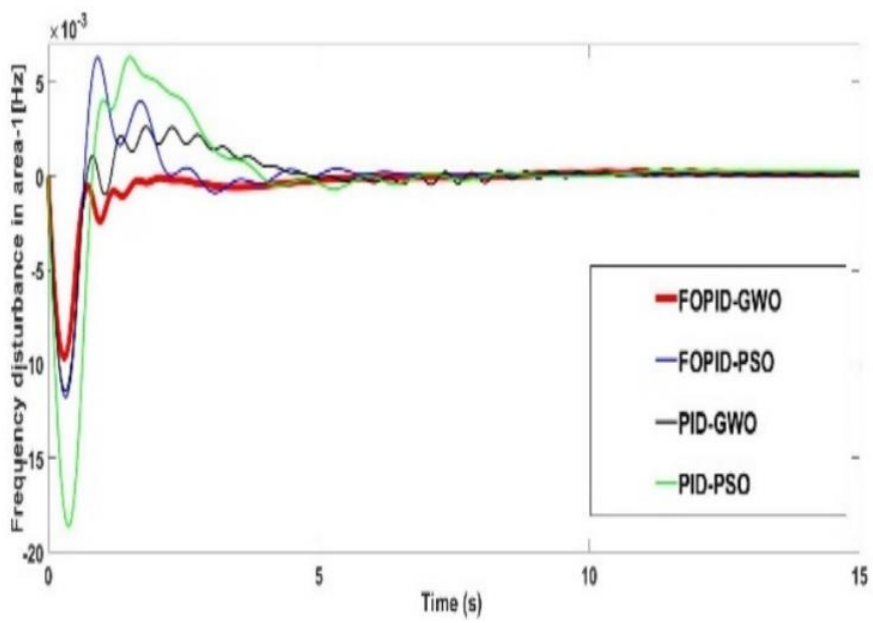

Figure (7)

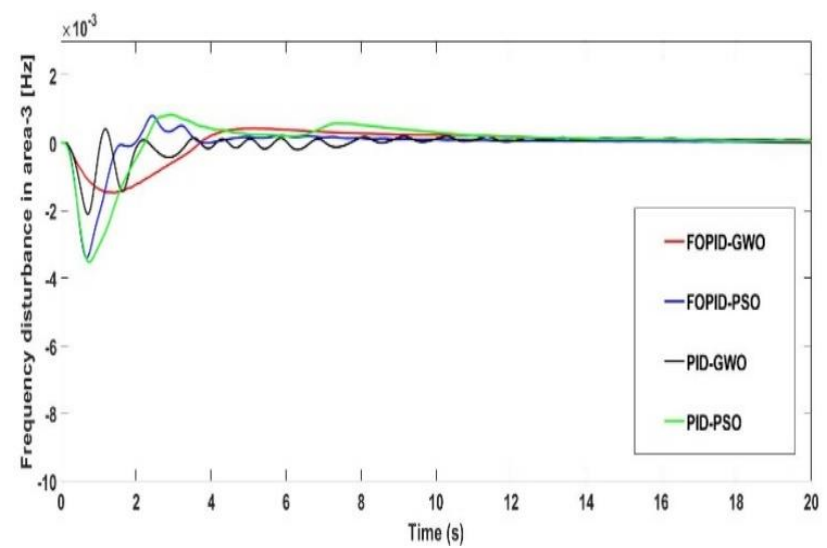

Figure (8)

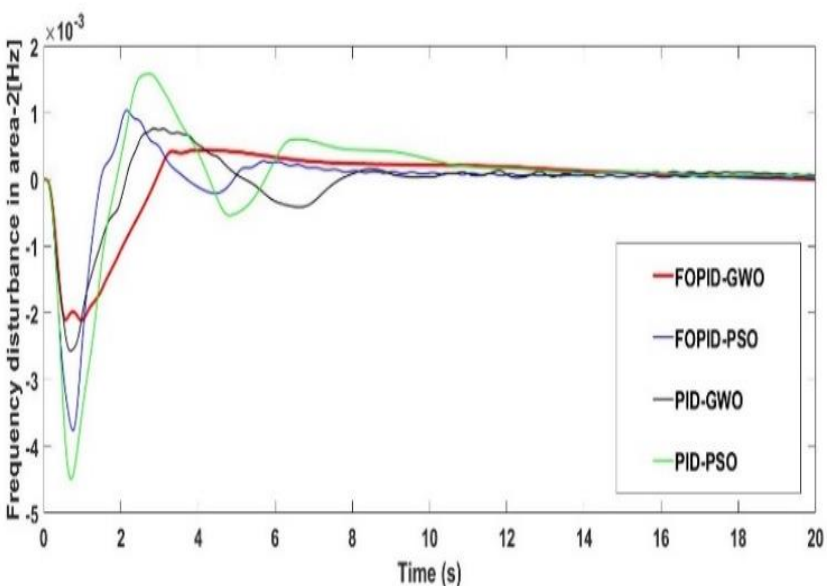

Figure (9)

Figure 7,8 and 9. Deviation of $\Delta f_{1}, \Delta f_{2}$ and $\Delta f_{3}$ for $\Delta P_{D 1}=0.01$ p.u

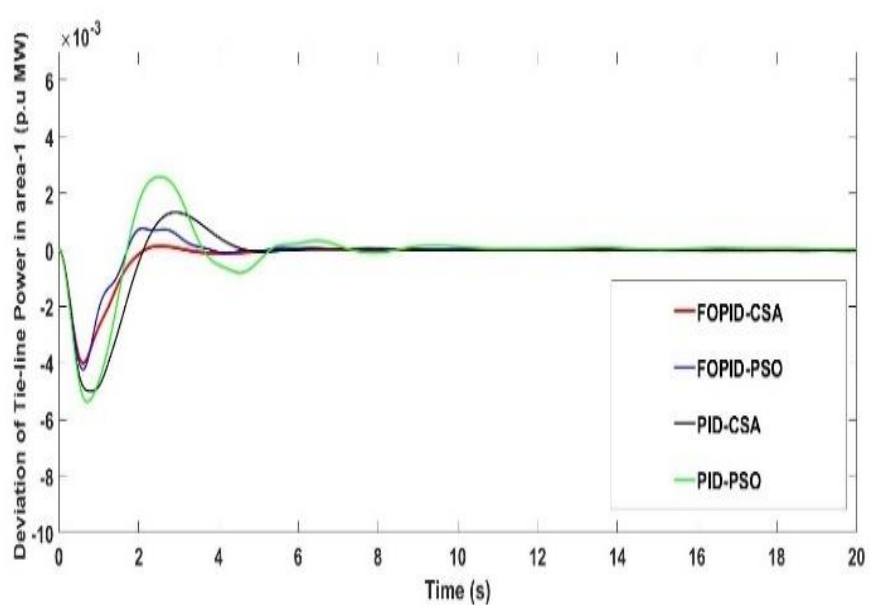

Figure (10)

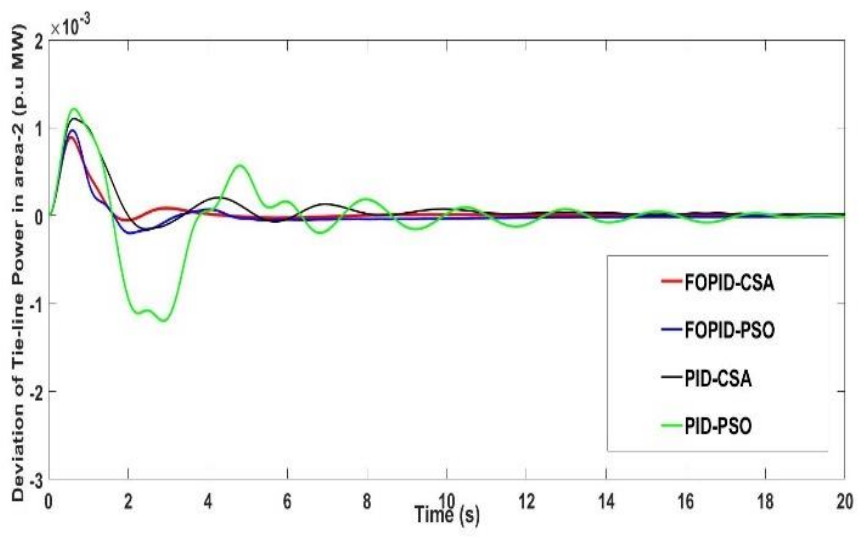

Figure (11) 


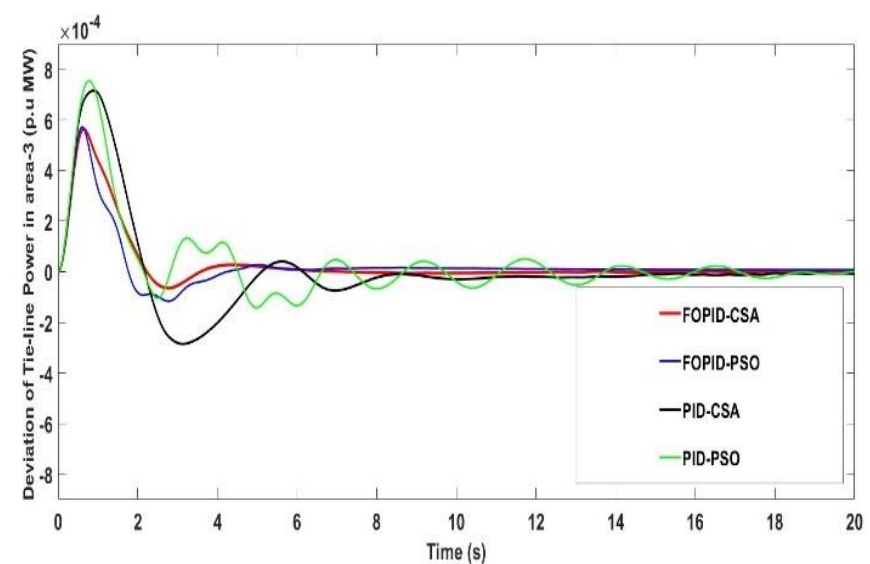

Figure (12)

Figure 10,11and 12. Deviation of $\Delta P_{\text {tie-1 }}, \Delta P_{\text {tie-2 }}$ and $\Delta P_{\text {tie-3 }}$ for $\Delta P_{D 1 .}=0.01$ p.u

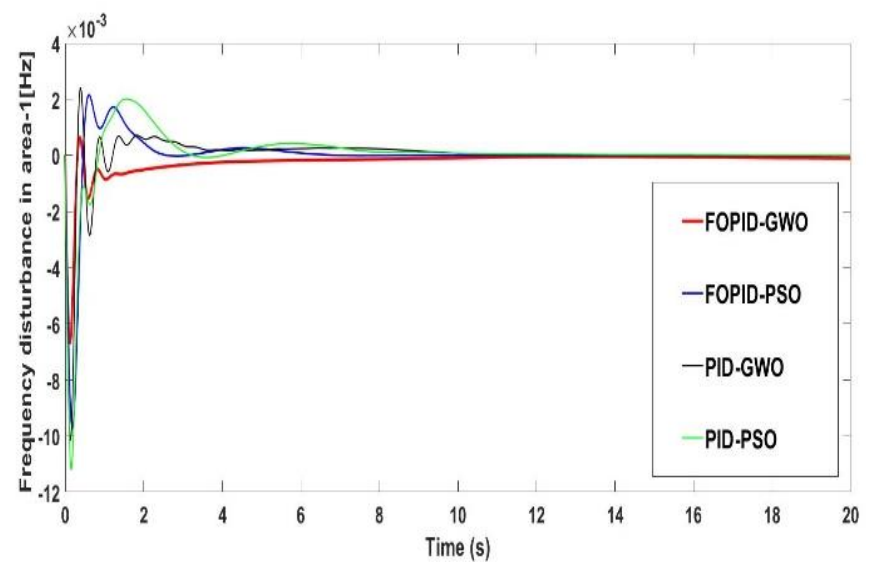

Figure (13)

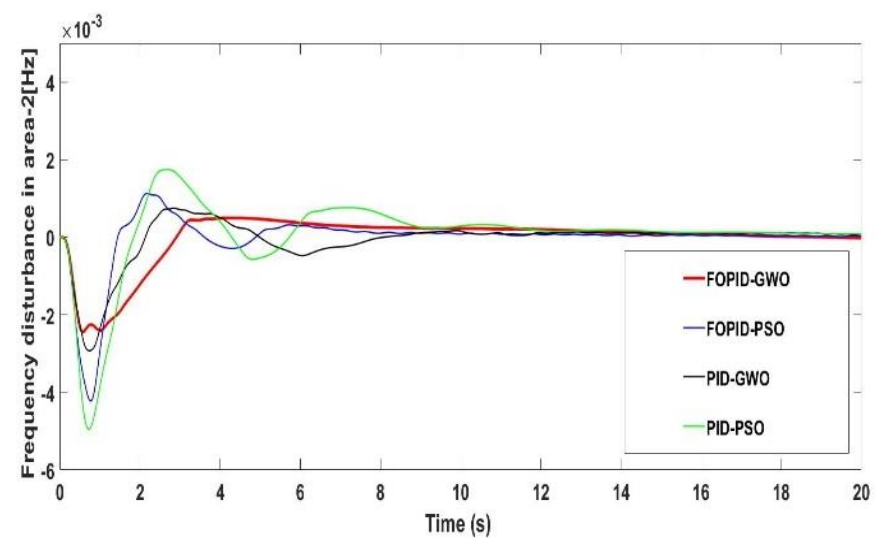

Figure (14)

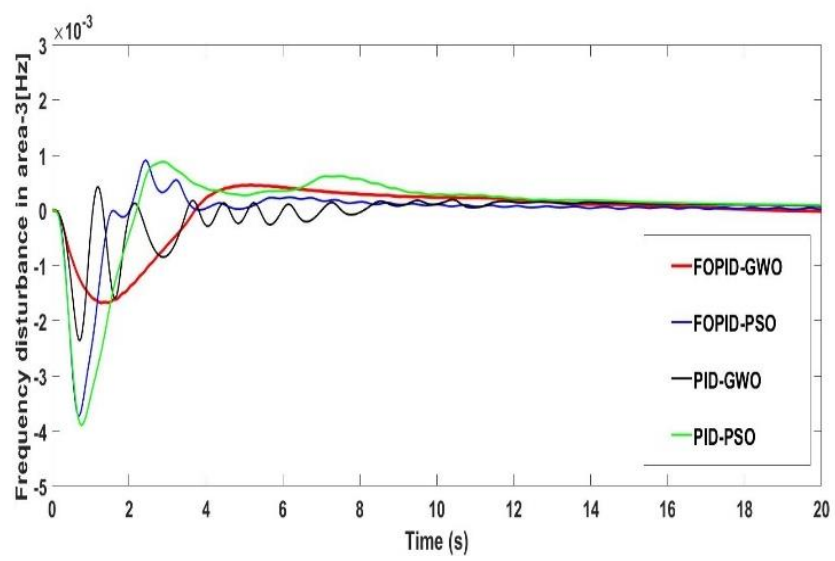

Figure (15)

Figure 13, 14 and 15. Deviation of $\Delta f_{1}, \Delta f_{2}$ and $\Delta f_{3}$ for $\Delta P_{D 1}=0.02$ p.u

\subsection{The Second Scenario}

The effect of the size of load disturbance on the AGC is investigated in this scenario. A chain of a step load of $2 \% \Delta P_{D 1}, 4 \% \Delta P_{D 1}, 6 \% \Delta P_{D 1}, 8 \%$ $\Delta P_{D 1}$ and $10 \% \Delta P_{D 1}$ consequentially is applied to power pool-1(Reheat, Gas and Hydro). The dynamic performance of the deviation in frequency and the tie-lines power exchange deviation responses in the three power pools are shown in figures (13,14 and 15) consequentially. It is clear from these figures that the suggested $P I^{\lambda} D^{\mu}$ controller using Grey wolf optimization (GWO) still superior compared with the other controllers. In addition to, the tuning of the controller provided by (GWO) algorithm is best obtained by using PSO algorithm as in table-3. As well as it is important to observe that the other controller PID adjust by PSO algorithm is fail to eliminate the exchange in tie-lines power and frequency error for a relatively large step load demand disturbance $8 \% \Delta P_{D 1}$ and $10 \% \Delta P_{D 1}$.

\subsection{The Third Scenario}

The third scenario is aimed to view the dynamic performance of the suggested $\left(P I^{\lambda} D^{\mu}\right)$ controller using (GWO) with varicose range of load disturbance, the algorithm applied alone on the three power pools system (Reheat, Gas and Hydro) with the step load disturbance change linear from $1 \% \Delta P_{D 1}$ to $10 \% \Delta P_{D 1}$ in the first 
power pool. The deviation in the frequency to the three pools and the tie-lines power exchange deviation are shown in figures 16,17 and18. As shown from these figures, the suggested algorithm is capable of eliminating the steady state tie-lines power exchange and the steadystate frequency errors. It desires to note that for a relatively large step load demand disturbance of $10 \% \Delta P_{D 1}$ the settling time may be longer with a high peak over shoot.

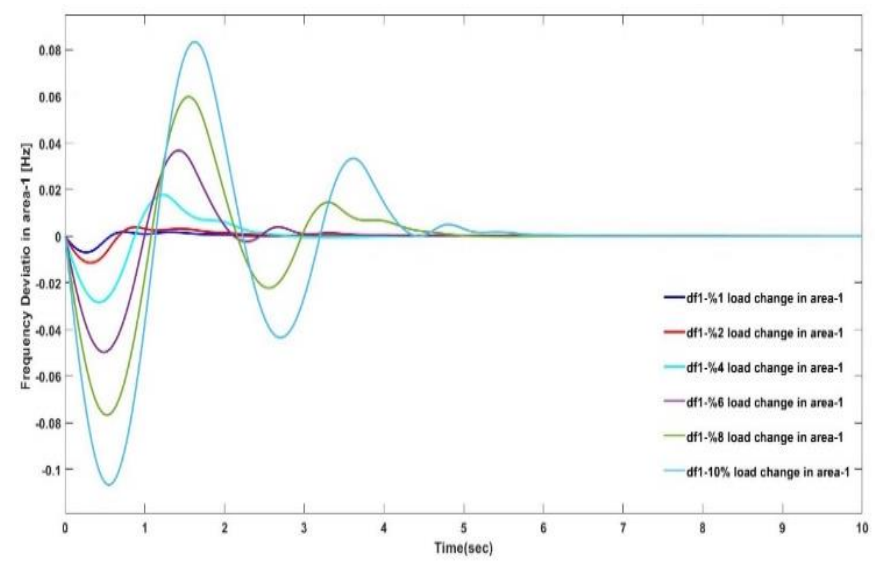

Figure 16. Deviation of $\Delta f_{1}$ for $(1-10) \%$ of $\Delta P_{D 1}$

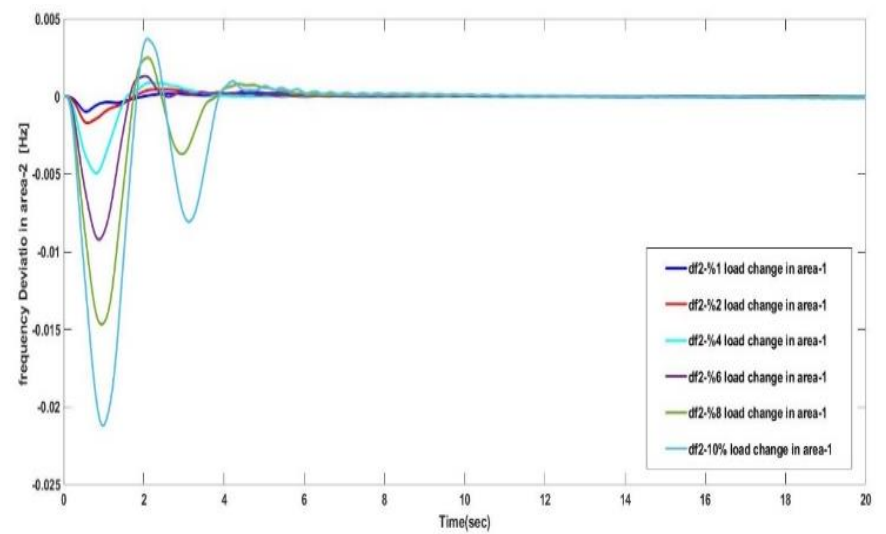

Figure 17. Deviation of $\Delta f_{2}$ for $(1-10) \%$ of $\Delta P_{D 1}$

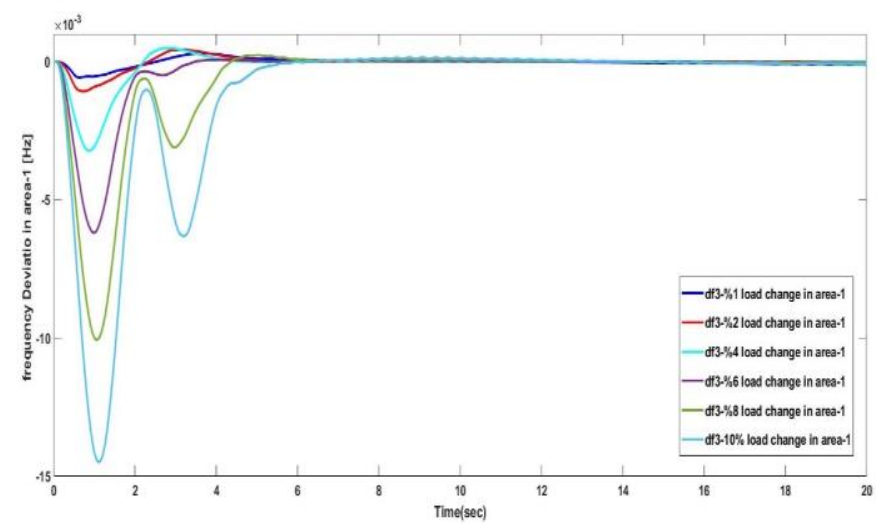

Figure 18. Deviation of $\Delta f_{3}$ for $(1-10) \%$ of $\Delta P_{D 1}$

\section{Conclusion}

A robust fractional controller PID is suggested for maintaining a constant frequency and tielines power exchange. The suggested control algorithm applied to a multi power pools (Reheat, Gas and Hydro) systems. The nonlinear constraints like GRC, boiler dynamics and GDB of the different plants implemented in the simulation. An evolutionary algorithm called Grey wolf optimization (GWO) algorithm has been used to set up the optimal controls parameters, the frequency bias factor (B) and droop regulation $(\mathrm{R})$, consequentially. The updated integral time absolute errors (UITAE) were selected as a performance index. A comparison of the dynamic performance obtained by the suggested algorithm made with these obtained by applying conventional PID controller. It was found that the suggested controller algorithms are effective in the enhancement of the dynamic performance in terms of the settling time, peak over shoot for a wide variety of disturbances. Evaluation of the robustness of the suggested algorithm carried out by applying it on a simultaneous step load disturbance on three power pool. It can be concluded that the setting of the frequency bias factor $\mathrm{B}$ based on a simultaneous tuning with controllers' parameters and droop regulation is important to get the best dynamic performance up to a relatively large step load disturbance.

\section{ACKNOWLEDGMENTS}

The authors would like to thank Mustansiriyah University (www.uomustansiriyah.edu.iq) Baghdad-Iraq for its support in the present work paper.
Abbreviations
PID Proportional Integral Derivative
$\Delta P_{m 1} \quad$ mechanical power deviation for the area $i(\mathrm{pu})$
LFC Load Frequency Control
$\Delta P_{c i} \quad$ power deviation of area $\mathrm{i}$ 


$\begin{array}{ll}\text { AGC } & \text { Automatic Generation Control } \\ \Delta P_{L i} & \text { load variation of area i } \\ \text { FO-PID } & \text { Fractional Order Proportional Integral Derivative } \\ T_{P i} & \text { power system time constant (s) } \\ \text { ACE } & \text { Area Control Error } \\ K_{P i} & \text { power system gains constant } \\ \text { GRC } & \text { Generation Rate Constraint } \\ T_{R i} & \text { reheater time constant (s) } \\ \text { GDB } & \text { Governor Dead Band } \\ T_{T i} & \text { steam turbine time constant (s) } \\ \text { ISE } & \text { Integral of Squared Error } \\ k_{R i} & \text { coefficient of reheater steam turbine } \\ \Delta f_{i} & \text { frequency deviation of area } i(\mathrm{~Hz}) \\ T_{G i} & \text { steam turbine speed governor time constant (s) } \\ B_{i} & \text { frequency bias constant of area } i(\mathrm{p} . \mathrm{MW} / \mathrm{Hz}) \\ R_{i} & \text { speed regulation value }(\mathrm{Hz} / \mathrm{pu}) \\ D_{i} & \Delta P_{D i} / \Delta f_{i} \text { (p.u MW/Hz) } \\ \beta_{i} & \text { Area frequency response characteristics of } \mathrm{i} \\ & \left(=D_{i}+1 / R_{i}\right)\end{array}$

\section{Conflict of Interest}

The authors confirm that the publication of this research causes no conflict of interest.

\section{References}

1. Yamashita $\mathrm{K}$ and Tanigouchi $\mathrm{T}$ "Optimal observer design for LFC" 1986 Electrical Power \& Energy Systems. Vol 8, No. 2, 93.

2. Hsu Y Y and Chan W C "Optimal variable structure control of interconnected hydrothermal power systems" 1984 Electrical Power \& Energy Systems. Vol 6, 221

3. Aldeen $M$ and Trinn $H$ "Load-frequency control of interconnected power systems via constrained feedback control schemes" 1994 Computers \& Electrical Engineering. Vol 20, No. 2, 71

4. Yang, T. C., Cimen, H., and Zhu, Q. M. "Decentralized load frequency controller design based on structured singular values" 1998 IEE Proceedings Generation, Transmission, Distribution-C. Vol 1457

5. Hassan M F, Abouelsoud A A and Solim H $M$ "Constrained Load-frequency Control" 2008 Electric Power Components and Systems. Vol 36, 266

6. Hari L, Kothari M L and Nanda J 1981 "Sampled-data automatic generation control of interconnected reheat thermal systems considering generation rate constraint" IEEE Transactions on Power Apparatus and Systems PAS-100 No.5 2334.

7. Ibraheem, Kumar $\mathrm{P}$, Hasan $\mathrm{N}$ and Nizamuddin "Sub-optimal Automatic Generation Control of Interconnected Power System Using Output Vector Feedback Control Strategy" 2012 Electric Power Components and Systems. Vol 40, 67

8. Yamashita $\mathrm{K}$ and Tanigouchi $\mathrm{T}$ "Optimal observer design for load-frequency control" 1986 International Journal on Electrical Power \& Energy Systems. Vol 8, No. 2

9. Sharma G, Nasiruddin I, Niazi K R and Bansal R C “Optimal AGC of a multi-area power system with parallel AC/DC tie lines using output vector feedback control strategy" 2016 Electrical Power Systems Research. Vol 81, 22.

10. Yang $\mathrm{M}$ and $\mathrm{Lu} \mathrm{H}$ "Sliding mode loadfrequency controller design for dynamic stability of large- scale interconnected power systems "1999 Proceedings of the IEEE International Symposium on Industrial Electronics, Bled, Slovenia 13162

11. Vrdoljak K, Peric N and Petrovic I "Sliding mode-based load-frequency control in power Systems" 2010 Electric Power Systems Research 80514

12. Al-Hamouz Z, Al-Duwaisha $\mathrm{H}$ and AlMusabi N "Optimal design of a sliding mode AGC controller: interconnected model” 2011 Electric Power Systems Research 8114

13. Pan $\mathrm{C} T$ and Lian $C \mathrm{M}$ "An adaptive controller for power system load-frequency control" 1989 IEEE Transaction on Power Systems. Vol 4, 122

14. Jiang H, Dorsey J F, Bond J and McClley J $M$ "Global robust adaptive control of power systems" 1994 IEE Proceedings Generation, Transmission, Distribution-C. Vol 141,429

15. Wang Y, Zhou R and Wen C "New robust adaptive LFC with system parameters uncertainties" 1994 IEE Proceedings Generation, Transmission, Distribution-C. Vol 141,184 
16. Talaq $\mathrm{J}$ and Al-Basari $\mathrm{F}$ “Adaptive fuzzy gain scheduling for load frequency control" 1999 IEEE Transaction on Power Systems. Vol 14, 145

17. Kazemi,M. H., Karrari, M. and Menhaj,M. B. "Decentralized robust adaptive output feedback controller for power system LFC "2002 Electrical Engineering Journal 8475 Zribi

18. S., C, Chandrasekhar Yammani and Sydulu Maheswarapu. "LFC of Multi-microgrid System considering Renewable Energy Sources Using Grey Wolf Optimization.” Smart Science 7 (2019): 198 217.

19. Mirjalili, Seyedali \& Mirjalili, Seyed \& Lewis, Andrew. (2014). Grey Wolf Optimizer. Advances in Engineering Software. $69.66-61$. 10.1016/j.advengsoft.2013.12.007.

20. Ibraheem, Kumar P and Kothari D P "Recent Philosophies of Automatic Generation Control Strategies in Power Systems" 2005 IEEE Transaction on Power Systems. VOL. 20346

21. Shankara R, Pradhanb S R, Chatterjeec K and Mandalc $M$ "A comprehensive state of the art literature survey on LFC mechanism for power system" 2017 Renewable and Sustainable Energy Reviews 76 118....

22. Alovic' M S C'. Stefanov $P C^{r}$ and Obradovic N M "Automatic correction of the systematic error on AGC regulators due to tie-line losses" 2008 European Transactions on Electrical Power Vol 18281

23. Gupta E and Saxena A "Grey wolf optimizerbased regulator design for automatic generation control of interconnected power system" 2016 Cogent Eng. 31

24. Vijaya Chandrakala K R M and Balamurugan $\mathrm{S}$ "Simulated annealing based optimal frequency and terminal voltage control of multi-source multi area system" 2016 International Journal of Electrical Power and Energy Systems 78, 823.

25. Ali E S and Abd-Elazim S M "Bacteria foraging optimization algorithm-based load frequency controller for interconnected power system" 2011 International Journal of
Electrical Power and Energy Systems 33, 633

26. Faris H, Aljarah I, Al-Betar MA, et al. Grey wolf optimizer: a review of recent variants and Applications. Neural Compute Appl. 2018;30(2):413-435.

27. Golpira H, Bevrani $H$ and Golpira $H$ "Application of GA optimization for automatic generation control design in an interconnected power system" 2011 Energy Conversion Management 522247

28. Nanda J, Mishra S, Saikia Lalit Chandra "Maiden application of bacterial foragingbased optimization technique in multiarea automatic generation control" 2009 IEEE Transaction on Power Systems. Vol 24, 602

29. Naidu K, Mokhlis $\mathrm{H}$ and Bakar AH "Multiobjective optimization using weighted sum Artificial Bee Colony algorithm for Load Frequency Control" 2014 International Journal of Electrical Power Energy Systems 55657

30. Roy R, Bhatt $\mathrm{P}$ and Ghoshal S P "Evolutionary computation based three-area automatic generation control" 2010 Expert Systems with Applications. Vol 37, 5913

31. Zamani A, MasoudBarakati S, and YousofiDarmian S "Design of a fractional order PID controller using GBMO algorithm for loadfrequency control with governor saturation consideration" 2017 IAS Transactions

32. Shiva C K and Mukherjee V "Design and analysis of multi-source multi-area deregulated power system for automatic generation control using quasi-oppositional harmony search algorithm" 2016 International Journal of Electrical Power Energy Systems 80382

33. Kumar N, Kumar V, and Tyagi B "Multi area AGC scheme using imperialist competition algorithm in restructured power system"2016 Applied Soft Computing, vol. 48160

34. Li M, Zhou P, Zhao Z and Zhang J "Twodegree-of-freedom fractional order-PID controllers design for fractional order processes with dead-time"2016 ISA Transactions. 61147

35. Dash P, Saikia L C and Sinha N "Automatic generation control of multi area thermal 
system using Bat algorithm optimized PDPID cascade controller" 2015 International Journal of Electrical Power and Energy Systems. 68364

36. Dash P, Saikia L C and Sinha N "Flower pollination algorithm optimized PI-PD Cascade controller in automatic generation control of a multi-area power system" 2016 International Journal of Electrical Power and Energy Systems. 82 (2016) 19

37. Sahu R K, Chandra Sekhar G T and Panda S "DE optimized fuzzy PID controller with derivative filter for LFC of multi-source power system in deregulated environment" 2015 Ain Shams Engineering Journal, 6 (2015) 511

38. Saikia L C, Sinha N, and Nanda J "Maiden application of bacterial foraging based fuzzy IDD controller in AGC of a multi-area hydrothermal system" 2013 International Journal of Electrical Power and Energy Systems 4598

39. Kothari M L, Nanda $J$ and Lakshman $H$ 1996"Selection of sampling period for automatic generation control" Electric Machines \& Power Systems 25 No.10 1036

40. Hari L, Kothari M L and Nanda J 1991“Optimum selection of speed regulation parameters for automatic generation control in discrete mode considering generation rate constraints" IEE Proceedings-C 138 No.5 401

41. Saravuth P, Issarachai N, Suwan R, Prinya T 2006 "Design of optimal fuzzy logic-based PI controller using multiple tabu search algorithm for load frequency control" International Journal of Control, Autom, Syst 4 No. 2155

42. Chown GA and Hartman RC 1998“Design $\&$ experience of fuzzy logic controller for Automatic Generation Control (AGC)" IEEE Transaction on Power Systems 13 No.3 965

43. Indulkar CS and Raj Baldev 1995“Application of fuzzy controller to automatic generation control" Electric Machines \& Power Systems 23209

44. Ghoshal S P and Goswam S K 2003“Application of GA based optimal integral gains in fuzzy based active power- frequency control of non-reheat and reheat thermal generating systems" Electric Power Systems Research 6779

45. Djukanovic M, Novicevic M, Sobajic DJ, Pao YP 1995“Conceptual development of optimal LFC using artificial neural networks and fuzzy set theory" International Journal of Engineering Intell Syst Electr Eng Commun 3 No.2 965

46. Baghya Shree S and Kamaraj N "Hybrid Neuro Fuzzy approach for AGC in restructured power system" 2016 International Journal of Electrical Power and Energy Systems 74274

47. Yang S, Huang C, Yu Y, Yue D, and Xin J "Load Frequency Control of Interconnected Power System via Multi-Agent System Method" 2017 Electric Power Components and Systems, 00(00):1-13, 2017

48. Debbarma S, Saikia L C, and Sinha N "Solution to automatic generation control using firefly algorithm optimized $\mathrm{I} \lambda \mathrm{D} \mu$ controller" 2014 ISA Transactions 53358

49. Debbarma S, Saikia L C, and Sinha N "Automatic generation control using two degree of freedom fractional order PID controller" 2014 ISA Transactions 58120

50. Delassi A, Arif S, and Mokrani L "Load frequency control problem in interconnected power systems using robust fractional PI $\lambda D$ controller" 2018 Ain Shams Engineering Journal 977.

51. Kundur P "Power System Stability and Control" McGraw Hill, New York 1994.

52. Elgerd O I "Electric Energy System Theory: An Introduction" McGraw Hill, New York, 1971.

53. Muwaffaq IA. Load Frequency Control and Automatic Generation Control using fractional order controllers. Electr Eng 2010;91: 357-68.

54. Yang, X.-S.; Deb, S. Cuckoo search via Lévy flights. In the 2009 World Congress on Design \& Biologically Based Computation, in Proceedings, Coimbatore, India, 9-11 Dec. 2009; pp. 210-214. 
APPENDIX 1.

$f=60 \mathrm{~Hz}, \mathrm{~T}_{\mathrm{Gi}}=0.08 \mathrm{~s}, 2 \mathrm{H}_{\mathrm{i}}=0.1666 \mathrm{~s}, \mathrm{~T}_{\mathrm{ri}}=10 \mathrm{~s}$,

$\mathrm{T}_{\mathrm{Ti}}=0.3 \mathrm{~s}, \mathrm{D}_{\mathrm{i}}=0.00833 \mathrm{p}$. u $M W / H z, \mathrm{~K}_{\mathrm{r}}=0.5, \mathrm{~T}_{\mathrm{pi}}=20 \mathrm{~s}$

$\mathrm{K}_{\mathrm{pi}}=120 \mathrm{~Hz} /$ pu MW, primaryloading $=50 \%, \mathrm{~T}_{\mathrm{ij}}=0.086$.

\section{A. Boiler dynamics}

$\mathrm{T}_{\mathrm{d}}=0, \mathrm{~K}_{1}=0.85, \mathrm{~K}_{2}=0.095, \mathrm{~K}_{3}=0.92, \mathrm{~T}_{\mathrm{f}}=10$,

$\mathrm{T}_{\mathrm{RB}}=69, \mathrm{C}_{\mathrm{B}}=200, \mathrm{~K}_{\mathrm{IB}}=0.03, \mathrm{~T}_{\mathrm{IB}}=26$.

\section{B. Non-linearities}

The nonlinear GRC \& GDB limitations took into consideration in this analyze are Indicated below: GRC $=\mp 0.03$ per minutes $=0.0005 \mathrm{p} . \mathrm{u} \mathrm{MW} / \mathrm{min}$ and $\mathrm{GDB}=\mp 0.0336 \mathrm{~Hz}$. 